\title{
The Other Side of Goal Orientation and Training Outcomes: Mediating Role of Training Motivation
}

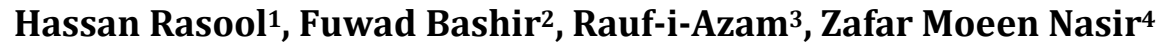 \\ ${ }^{1}$ Department of Management Science, Pakistan Institute of Development Economics, Islamabad, Pakistan \\ ${ }^{2}$ MaxFoster Global, Islamabad, Pakistan \\ ${ }^{3}$ Education University, Lahore, Pakistan \\ ${ }^{4}$ American University, Dubai, UAE \\ Email: rasool.hassan@gmail.com, fuadawan@yahoo.com, rauf.i.azam@gmail.com, zfr nasir@yahoo.com
}

Received 9 July 2015; accepted 24 October 2015; published 27 October 2015

Copyright (C) 2015 by authors and Scientific Research Publishing Inc.

This work is licensed under the Creative Commons Attribution International License (CC BY).

http://creativecommons.org/licenses/by/4.0/

(c) (i) Open Access

\section{Abstract}

The effect of goal orientation on training motivation and training outcomes is measured from a sample of 216 employees. The empirical evidence confirms that state goal orientation is a three dimensional construct (performance, learning and refusal) and it predicts training motivation and training outcomes. It establishes that training programs in organizations have learning and less explored "non-learning" outcomes. And training motivation mediates the relationship between goal orientation and both outcomes. Implications of these new insights for academicians and practitioners are discussed.

\section{Keywords}

\section{Goal Orientation, Training Motivation, Training Outcomes}

\section{Introduction}

It is an avenue of critical importance for academicians and practitioners to understand the phenomenon of training effectiveness and to identify factors that affect the outcomes of a training program. From organizational perspective, training programs are expected to reap different benefits like employee development and improved employee performance [1] that in return pave way to greater organizational effectiveness and performance. This value does not come free for organizations rather huge tangible and intangible costs are associated with training endeavors. It is believed that organizational performance discrepancies (OPD) can be overcome with the help of 
effective training programs [2]. Organizations tend to be very considerate and sensitive in pursuing training initiatives but give lesser attention to gauge the effect of training program on employees beyond the conventional skill, knowledge and ability (SKAs).

For organizations, training is a systematic process of providing an opportunity to learn SKAs for current or future jobs. But from a trainee's perspective, a training program is much more than the acquisition of job related skills and knowledge [3] and effectiveness of a training program should not be restricted to the acquisition of skills and knowledge [4]. The gap between organizations and their employee's perception of training program affect the evaluation of training program by each. We believe that unless organizations understand the way employees perceive and act towards a training program and the consequent holistic outcomes, effectiveness of training programs may be partially judged. And any decision made on the conventional evaluations may not be beneficial for organizations. It is important for organizations to understand the factors that affect goal setting (reason of a set goal) of trainees and how these set goals affect their willingness to participate (training motivation) and all possible outcomes.

This study, from a trainee's perspective, explains the motivation and outcomes (non-learning) beyond the traditional SKAs (learning) of a training program. Drawing on the goal orientation theory, it explains the factors that affect the development of goal orientation in training contexts. Furthermore, it explains that how motivation and outcomes of training programs are affected by these goal orientations. And finally it discusses the implications of these new insights for practitioners and academic researchers.

\section{Conceptual Framework}

The conceptual framework for this study, shown in Figure 1, based on social exchange and goal setting theory to propose three dimensional goal orientations, augment training motivation theory, which is based on [5] and [6], with learning and non-learning outcomes. Previous research has not specifically studied the impact of goal orientation on training motivation and outcomes or for the purpose of determining the relationship among three dimensional goal orientation, training motivation and non-learning outcomes. See Figure 1 below.

\section{Literature Review}

\subsection{Perception and Goal Orientation}

Goal orientation explains the way individuals seek the fulfillment of their goals. Role of goal orientation is studied with respect to many organizational phenomena including training [7] [8]. Goal orientation is one the key internal factor that determines trainee's willingness to exert energy in a training program. Trainees join a training program with not only different goals but with different goal orientations [9]. Goal orientation forms a framework of individual's reaction to and interpretation of an event [10]-[13]. Goal orientation explains the way individuals seek the fulfillment of their goals. Role of goal orientation is studied with respect to many organizational phenomena including training [7] [8], feedback [14] [15]; organizational and individual learning [16], and effectiveness [9].

Dweck [10] identified two goal orientations and were termed as mastery (learning) and performance. Mastery refers to a training reaction when an individual focus on acquisition of KSAs while performance goal orientation refers to a reaction when an individual focus on the improvement of one's performance out of a training endeavor. These goal orientations were further divided into two categories as approach and avoid. Individual with an approach orientation seeks to maximize learning or performance and individuals with avoid goal orientations tends to counter intrapersonal incompetence or strive to avoid the tag of a worst performer. Elliot \& McGregor, [13] reclassified goal orientation as competence and competence evaluation whereby competence goal orientation includes performance and mastery while competence evaluation goal orientation includes avoid and approach.

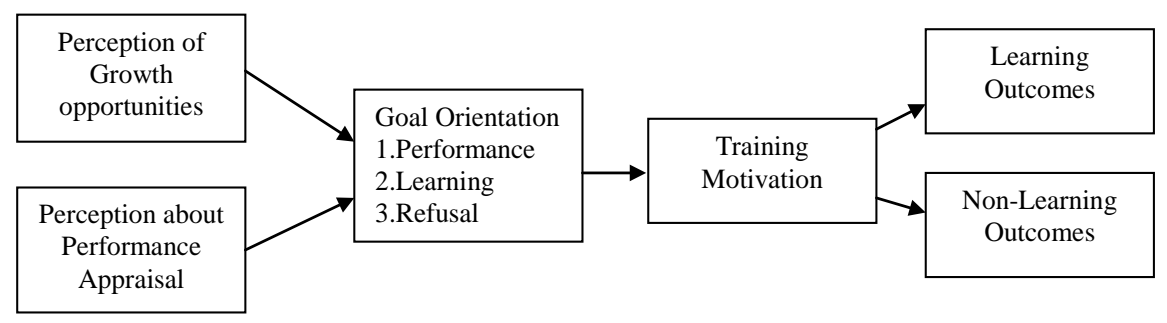

Figure 1. Conceptual framework: goal orientation and training outcomes. 
Explanation provided by Dweck [10] (see [17] for a review) suggested that individuals held either mastery or performance goals, more recent conceptualizations (e.g. [13]) have suggested that avoid and approach mastery and performance goals reveal four separate, but interrelated dimensions, such that being higher on one dimension does not mean that the individual is evenly lower on another dimension. Furthermore both competence and competence evaluation goal orientations cumulatively form the overall goal orientation of an individual.

For the purpose of this study, we believe that earlier conceptions do not represent, at least in training contexts, the true picture of goal orientation because goal orientation in earlier studies is always assumed as a training reaction in "achievement" situations. We believe that being sent to a training program is not always perceived as an achievement situation by the employees. And earlier conceptions of avoid or competence evaluation dimensions of goal orientation are limited in understanding the overall goal orientation. We, in this study, do not limit our analysis to some given "achievement" reaction. We have studied a reaction that is perceived by the trainee itself to form a three dimensional construct of goal orientation. Furthermore this study also takes into account the factors that may develop such reactions that cannot be limited to competence and competence evaluation. These are circumstances whereby individuals may also refuse any performance or learning criteria in determining their goals by focusing on seeking leisure and time out of work. This reveals a third dimension of goal orientation that is beyond learning and performance and may be termed as "refusal goal” orientation.

Antecedent of goal orientation is a widely researched area. Cognitive ability, implicit theory of intelligence, need for achievement, the Big Five personality characteristics, self-esteem, and general self efficacy are identified as determinants of goal orientation [18]. Beyond these given antecedents, perception about organization and environment is another important determinant of goal orientation [19].

For many years, social exchange theory [20] is applied to investigate and explain a variety of work attitudes, and behavioral outcomes [21]. The employment relationship allows the employee to develop a perception about the system of the organization [22] and this perception govern the subsequent reaction of individuals. It is assumed that these perceptions along with different dispositional factors determine the overall goal orientation of individuals.

Perceived environmental (contextual) factors (e.g. organizational systems, growth opportunities) that are believed to exist or be encountered [23] develop goal orientation for an individual.

For the purpose of this study, drawing from social exchange theory it is assumed that interaction of employees with their surroundings develop a perception about organizational systems and the overall environment and this "state" ultimately give shape to different goal orientations. Specifically two factors are taken into consideration i.e. perception about performance appraisal systems and perception about growth opportunities. Individuals who perceive that performance appraisal systems are not in place will feel no threat of evaluations. Similarly individuals, who perceive no growth opportunities, will react in ways where learning new things is not a major concern. Such as when they are exposed to a training program, will develop an orientation that neither ensures performance and nor learning and will tend to develop another type of orientation say "refusal”. On the other hand if individuals perceive that there are growth opportunities and performance appraisal system is in place, they will tend to develop learning and performance goal orientations. More specifically, individual who perceives that there are growth opportunities, will tend to develop greater learning orientation and individuals who perceive that performance appraisal systems are in place will tend to develop greater performance orientation.

Performance goal orientation is characterized by an individual perception whereby one perceives that performance evaluation system is in place and there are favorable opportunities in the environment. Individuals high on performance goal orientation tend to reap favorable judgments or avoid negative judgments of performance.

Learning goal orientation is characterized by an individual perception whereby one perceives that performance evaluation system is in place and there are favorable opportunities in the environment. Individuals high on learning goal orientation tend to master a new competency or avoid intrapersonal incompetence.

Refusal goal orientation is characterized by an individual perception whereby one perceives that performance evaluation system is not efficient and there are no significant opportunities in the environment. Individuals high on refusal goal orientation tend to neither reap favorable judgments nor avoid negative judgments of performance. Furthermore they neither strive to master new competency nor try to avoid interpersonal incompetence. This competence refusal goal orientation will prevail in circumstances whereby training is perceived as neither a facilitator nor an impeder for career growth and performance improvement.

H1a. A significant and positive relationship exists between perceived growth opportunities and learning goal orientation. 
H1b. A significant and positive relationship exists between perceived effectiveness of performance evaluation system and learning goal orientation.

H2a. A significant and positive relationship exists between perceived growth opportunities and performance goal orientation.

$H 2 b$. A significant and positive relationship exists between perceived effectiveness of performance evaluation system and performance goal orientation.

HЗa. A negative and significant relationship exists between perceived growth opportunities and refusal goal orientation.

H3b. A negative and significant relationship exists between perceived effectiveness of performance evaluation system and refusal goal orientation.

Keeping in view [13] conceptualization, the proposed three dimensions of goal orientation will commutatively form the overall goal orientation of an individual and is termed as "goal orientation composite" in this paper. Such as being high on one dimension may not necessary mean low on other dimension.

H4a. Perception of performance evaluation system is related to composite goal orientation.

$H 4 b$. Perception of growth opportunities is related to composite goal orientation.

\subsection{Goal Orientation and Training Motivation}

In a training context motivation is a goal directed inspiration and derives from trainee's personal needs and the decision processes they use to satisfy those needs. [2]. A number of predictive variables have been identified that affect the motivation towards a training program. External factors like work environment. (e.g. [24] [25], organizational climate (e.g. [5] [26], transformational leadership [27], overall organizational commitment and career planning [5], supervisory support, work policies, organizational environment (e.g. [28] and training design [24] have each been identified as factors that influence employee's motivation towards a training program.

Besides these external factors, individual factors are critical in the determination of training motivation and training outcomes [5]. A number of studies have been conducted to test the effect of personal mental ability (e.g. [5] [29]), self efficacy and personality (e.g. [5] [28] [30] and goal orientation (e.g. [31]).

Farr [32] and Payne [18] have suggested that performance goal orientation might be negatively related to training motivation if individuals infer that being sent to training reflects management's negative evaluation of their performance.

H5a. Performance goal orientation has a significant and negative relationship with training motivation.

Research has indicated that goal orientations affect learning outcomes and motivation in learning contexts with stronger effects for learning goal orientations (e.g. [10]) such as training. Much of this research has examined these effects for children and adolescents in academic and sports settings. However, research has demonstrated similar effects for goal orientations for adults in work settings (e.g. [33] [34].

H5b. Learning goal orientation has a significant and positive relationship with training motivation.

Perceived environmental (contextual) factors (e.g. organizational systems, growth opportunities) that are believed to exist or be encountered [23] develop refusal goal orientation of an individual. Refusal goal orientation is characterized by an individual's perception whereby one perceives that joining a training program neither reap favorable judgments nor avoid negative judgments of performance. And similarly a training program does not offer mastering of a new competency or a leverage to avoid interpersonal incompetence. This competence refusal goal orientation will prevail in circumstances whereby training is perceived as neither a facilitator nor an impeder for growth and performance improvement.

These Individual's perceptions regarding environmental factors also affect their motivation towards a training program [19]. Individuals with competence refusal goal orientation may still be motivated to join a training program as they seek time out of work pressure or change or to fulfill similar needs. Research has shown that job related stress and leisure seeking behavior has a positive relationship with absenteeism [35]. Individuals that seek time out of work are more prone to competence refusal goal orientation as they see training program as an opportunity to have a day off from job. In such cases training serves as a buffer to reduce work fatigue.

H5c. Refusal goal orientation has a significant and positive relationship with training motivation.

\subsection{Goal Orientation and Training Outcomes}

In general, beneficial effects have been observed for learning goal orientations on various training outcomes (e.g. 


\section{[16] [36].}

Individuals with learning orientation will tend to focus on the learning aspects of the training. These individuals perceive training as a learning opportunity and will be open to new experiences without pressure. They will get the benefit of socialization and ultimately will be fresher at the conclusion of the training. So training program will be beneficial experience for them and they will reap learning and non-learning benefits.

H6a. A positive and significant relationship exists between learning goal orientation and outcomes (learning and non-learning).

Individuals with performance goal orientation may perceive that being sent to a training program is a negative evaluation of one's performance. Furthermore they also believe that time spend on training will further increase their burden of work and they will be having limited time to execute the lag work because of time spent on training. These individuals tend to avoid any leisure at training neither look for socialization and are continuously burdened with the thoughts of work they left back in office. However they may be motivated to learn new things if they perceive that doing so will increase their performance evaluation.

H6b1. A positive and significant relationship exists between performance goal orientation and learning outcomes.

H6b2. A negative and significant relationship exists between refusal goal orientation and non-learning outcomes of a training program.

Cohen [37] found that trainees' training motivation will be enhanced if they feel that the training programs are beneficial. These benefits are translated on the basis of goal orientation. Individuals with refusal orientation seek non-learning benefits and training is perceived as a great opportunity to earn these benefits leading towards a greater motivation.

H6c1. A positive and significant relationship exists between refusal goal orientation and non-learning outcomes.

H6c2. A negative and significant relationship exists between refusal goal orientation and learning outcomes of a training program.

\subsection{Training Motivation and Training Outcomes}

A number of studies have sought the antecedents to and the mediatory effect of training motivation on training effectiveness (e.g. [5] [38] [39]. In training context, motivation influences the willingness of an employee to attend training [40] [41]. It can also affect a trainee's decision to exert energy toward the training program [42]. Furthermore it influences trainees' training performance and transfer outcomes [43] The important role of training motivation in training effectiveness has also been confirmed by several empirical studies (e.g. [27] [39] [43] [44]).

Outcomes of a training program is an avenue that is highly researched but to our knowledge, very few if no, studies consider the outcomes other than (SKAs) learning.

One critical determinant of training effectiveness is the trainees' level of training motivation [28] [30] [45]. Noe [46] suggested that characteristics such as motivation and attitudes are malleable individual difference factors that play a critical role in achieving training effectiveness. Even if trainees possess the ability to learn the content of a course, they may fail to benefit from training because of low motivation. From a trainee's perspective, a training activity is much more than the acquisition of job related skills and knowledge and it has certain non-learning outcomes [47]. Training professionals also believe that understanding of a training program should not be restricted to the acquisition of skills and knowledge [48].

These non-learning training outcomes combined with learning outcomes define the overall effectiveness of a training initiative. The beneficial effects of training are expected in terms of SKAs (learning outcomes), cultural and role changes, homogenization, and decrease of tensions and insecurities, motivation, commitment and conflict resolution in workplace (Non-learning outcomes) [49]-[52].

Learning is defined as a permanent change in one's behavior due to a given experience. We have used the term "Non-Learning" outcomes because we feel that the beneficial effects of training other than learning, do not bring in a permanent change in one's behavior. These effects are somewhat similar to the relaxation effect or absenteeism effects whereby an individual feels fresh and able to energize due to having a time out of work.

Training motivation has a significant and positive relationship with learning outcomes (e.g., [30] [38] [53][56]). However research has largely focused on the learning outcomes and other training outcomes (non-learning) like behavior change, motivation and attitudinal outcomes are rarely researched [5]. 
H7a. Training motivation has a positive and significant relationship with learning outcomes of a training program.

H7b. Training motivation has a positive and significant relationship with non-learning outcomes of a training program.

H8a. Training Motivation will mediate the relationship between composite goal orientation and learning outcomes.

H8b. Training Motivation will mediate the relationship between composite goal orientation and Non-Learning outcomes.

\section{Methods}

\subsection{Selection of Sample}

Because of the very nature of the study, we believed that to tap such insights we need to focus on off the job trainings conducted at remote locations from the offices. We contacted about sixty organizations on convenience basis that include textile, financial, telecom and governmental organizations. Respective HR or Admin department was requested to give us a list of such trainings and their participants. Based on the title of the training, common trainings were identified and a pool of study participants was organized. Out of this pool, we selected candidates on the basis of their availability and access. Thus a convenience sample of 300 individuals was contacted in person for data collection through a structured questionnaire. 216 questionnaires were successfully administrated with a response rate of 0.75 .

\subsection{Instruments}

\subsubsection{Trainee's Perception}

Perception about performance appraisal systems was measured through William and levy questionnaire [59]. This describes the extent to which employees perceive they understand the important aspects of performance appraisal systems related to their job. Modifications were made to collect information about employee's perceptions regarding the effectiveness of performance appraisal systems. The internal consistency reliability of this 3 item 7 point measure in the present sample was 0.92 . While perception about growth opportunities was measured through a four item 7 point scale and was internally reliable at 0.93 .

\subsubsection{Goal Orientation}

Goal orientation was measured through a 29 item measure. 16-item measure developed by Button [58] was used to access performance and learning goal orientation. An additional 13 item measure was used to access the refusal goal orientation.

Participants in the current study responded on a 7-point likert rating scale with values ranging from 1 (strongly disagree) to 7 (strongly agree). The internal consistency reliabilities of this measure in the present sample were 0.84 where separate internal reliabilities of performance, learning and refusal goal orientation were 0.95 , 0.94 and 0.95 respectively.

\subsubsection{Training Motivation}

A six item reduced form of sixteen items measure developed by Noe \& Wilk [41] was used to measure trainee's training motivation. The internal consistency reliability of this measure in the present sample was 0.95 .

\subsubsection{Training Outcomes}

Thirteen item 7 point likert scale measure was developed to access learning and non-learning outcomes. The internal consistency reliabilities of this measure in the present sample were 0.87 . Description of items for all measures is given in Appendix.

\subsection{Data Collection and Analysis}

Participation was voluntary and no incentives were offered in return for participation. The study was presented to employees as part of a program evaluation and continuous improvement effort. Participants to the training program were asked to complete 3 different questionnaires. First questionnaire assessed experience, tenure, de- 
signation, gender and Goal orientation. Second questionnaire measured the perceptions about organizational performance management systems and perception about growth opportunities and training motivation. The third questionnaire assessed the learning and non-learning outcomes of a training program. Three separate questionnaires were used to ensure that response may not be affected by the magnitude of the questionnaire.

\section{Factor Analysis}

All three questionnaires were input to evaluate that they represent separate entities. Varimax rotation was used to identify differences among factors. Few items loaded on different measures. These were removed from the questionnaire. Items that loaded with .48 or greater and are loaded on a single factor were short listed.

Finally it was confirmed that goal orientation dimensions are correlated but represent three distinct constructs. Similarly training outcomes i-e learning and non-learning are correlated but represent two distinct constructs.

\section{Results}

All respondents had attended at least three training prior to the study. Majority (80\%) of participants in this study were male while $20 \%$ were female.13\% of all participants were having less than four years of experience with the organization while respondents with 4 - 6 years were $60 \%$ and respondents with more than 15 years were $5.6 \%$. 44\% respondents were having experience of 3 - 4 years while $40 \%$ were having experience of 5 - 14 years and $11 \%$ were having experience of more than 15 years.

$8 \%$ of the respondents work with private limited companies while $39 \%$ with public limited companies and $52 \%$ were government employees. $4 \%$ were low level managers while 57\% were middle level and 39\% were high level managers.

It is evident from the correlation results (see Table 1) that perceived growth opportunities and perceived effectiveness of performance evaluation system is related to learning, performance and refusal goal orientation. Growth opportunities and effectiveness of performance evaluation system are positively related with learning and performance and are negatively related with refusal goal orientation.

\subsection{Main Effects}

Regression results in Table 2 confirm the impact of perception on performance, learning and refusal goal orientation. Goal orientation predicts the training motivation. Results also confirm the effect of training motivation on learning and non-learning outcomes.

Specifically, performance goal orientation has a significant and negative relationship with training motivation. Learning goal orientation has a significant and positive relationship with training motivation. Refusal goal orientation has a significant and positive relationship with training motivation. A positive and significant relationship exists between performance goal orientation and learning outcomes while a negative and significant relationship exists with non-learning outcomes. A positive and significant relationship exists between learning goal orientation and learning and non-learning outcomes. A positive and significant relationship exists between

Table 1. Mean, S.D. and correlations

\begin{tabular}{|c|c|c|c|c|c|c|c|c|c|c|}
\hline & MEAN & S.D. & GRO & PPS & PGO & LGO & RGO & $\mathrm{TM}$ & LRO & NLRO \\
\hline GRO & 3.8600 & 1.24350 & 1 & & & & & & & \\
\hline PPS & 3.8264 & 1.38917 & $0.517^{* *}$ & 1 & & & & & & \\
\hline PGO & 4.1325 & 1.34819 & $0.427^{* *}$ & $0.426^{* *}$ & 1 & & & & & \\
\hline LGO & 4.3553 & 1.16940 & $0.260^{* *}$ & $0.148^{*}$ & 0.001 & 1 & & & & \\
\hline RGO & 4.9879 & 1.18959 & $-0.382^{* *}$ & $-0.513^{* *}$ & $-0.412^{* *}$ & 0.123 & 1 & & & \\
\hline $\mathrm{TM}$ & 5.0934 & 1.75485 & 0.121 & $-0.180^{* *}$ & $-0.299^{* *}$ & $0.474^{* *}$ & $0.505^{* *}$ & 1 & & \\
\hline LRO & 4.5417 & 1.46072 & $0.562^{* *}$ & $0.526^{* *}$ & $0.405^{* *}$ & $0.420^{* *}$ & $-0.156^{*}$ & $0.334^{* *}$ & 1 & \\
\hline NLRO & 4.6111 & 1.53534 & $-0.326^{* *}$ & $-0.431^{* *}$ & $-0.232^{* *}$ & $0.395^{* *}$ & $0.358^{* *}$ & $0.280^{* *}$ & $-0.178^{* *}$ & 1 \\
\hline
\end{tabular}

${ }^{*}$ Correlation is significant at the 0.05 level (2-tailed). ${ }^{* *}$ Correlation is significant at the 0.01 level (2-tailed). GRO = Growth Opportunities, PPS = Perception about performance appraisal, PGO = Performance goal orientation, LGO = Learning goal orientation, RGO = Refusal goal orientation, TM $=$ Training Motivation, $\mathrm{LRO}=$ Learning Outcomes, NLRO $=$ Non-learning outcomes. 
Table 2. Testing main effect hypothesis.

\begin{tabular}{|c|c|c|c|}
\hline Variables & $\begin{array}{l}\text { Adjusted } R \\
\text { Square }\end{array}$ & $\begin{array}{l}\text { Std. Error of } \\
\text { the Estimate }\end{array}$ & Predictors \\
\hline $\begin{array}{l}\text { Performance } \\
\text { Goal orientation }\end{array}$ & 0.409 & 1.03667 & $\begin{array}{l}\text { Perception of Growth opportunity }(B=0.25, t=-4.94 \text {, Sig., } 0.000) \text {., Per- } \\
\text { ception of Performance System }(B=-0.18, t=4.96 \text {, Sig., 0.000). }\end{array}$ \\
\hline $\begin{array}{l}\text { Learning } \\
\text { Goal Orientation }\end{array}$ & 0.071 & 1.12699 & $\begin{array}{l}\text { Perception of Growth opportunity }(\mathrm{B}=0.41, \mathrm{t}=-5.94 \text {, Sig., } 0.000) \text {., Per- } \\
\text { ception of Performance System }(\mathrm{B}=-0.12, \mathrm{t}=-3.14 \text {, Sig., 0.05). }\end{array}$ \\
\hline $\begin{array}{l}\text { Refusal } \\
\text { Goal Orientation }\end{array}$ & 0.260 & 1.02312 & $\begin{array}{l}\text { Perception of Growth opportunity ( } B=-0.51, t=-5.94 \text {, Sig., } 0.000) \text {. } \\
\text { Perception of Performance System }(B=0.10, t=2.02 \text {, Sig., 0.05) }\end{array}$ \\
\hline Training Motivation & 0.435 & 1.31955 & $\begin{array}{l}\text { Refusal Goal Orientation }(B=-0.39, t=6.97 \text {, Sig., } 0.000) \text { Learning Goal } \\
\text { Orientation }(B=0.42, t=8.22 \text {, Sig., } 0.000) \text {, Performance Goal Orienta- } \\
\text { tion }(B=-0.13, t=-2.42 \text {, Sig., 0.016) }\end{array}$ \\
\hline Learning Outcomes & 0.107 & 1.38017 & Training Motivation $(\mathrm{B}=0.278, \mathrm{t}=5.18$, Sig, 0.000$)$ \\
\hline $\begin{array}{l}\text { Non-Learning } \\
\text { Outcomes }\end{array}$ & 0.074 & 1.47723 & Training Motivation $(\mathrm{B}=0.245, \mathrm{t}=4.272$, Sig, 0.000 ) \\
\hline
\end{tabular}

Table 3. Mediating role of training motivation.

\begin{tabular}{ccccc}
\hline Training Motivation as Mediator & M effect & SE Effect & CI 95\% & Z \\
Goal Orientation \& Learning Outcomes & 0.07 & 0.04 & $0.13,0.02$ & 3.12 \\
Goal orientation \& Non-Learning Outcomes & -0.10 & 0.05 & $-0.16,-0.05$ & -3.34 \\
\hline
\end{tabular}

refusal goal orientation and non-learning outcomes while a negative and significant relationship exists with learning outcomes. Training motivation has significant relationship with learning and non-learning outcomes of a training program.

\subsection{Mediation Analysis}

We employed bootstrap analysis developed by [57] and estimated 10,000 bootstrap samples. For testing mediation, 95\% confidence intervals were computed to identify whether the indirect effect is significantly different from zero at 0.5 significance. In cases where confidence interval is not zero, meditation effect is suggested. Preacher and Hayes's and Sobel test values and significance levels were as under

It was hypothesized (H8a) that training motivation will mediate the relationship between goal orientation and learning outcomes. Table 3 indicates the mediating role of training motivation in the relationship of goal orientation and learning and non-learning outcomes. It shows that the relation between Goal Orientation and learning outcomes is mediated by training motivation. Furthermore, H8b was also validated as relation between goal orientation and non-learning outcomes is also mediated by training motivation.

\section{Discussion}

Keeping in view the results of this research it can be safely inferred that goal orientation construct should include refusal goal orientation as a third dimension of goal orientation. Refusal goal orientation has a unique relationship with training motivation. It has strong positive relationship with training motivation yet it reaps significant non-learning outcomes. These results are partially consistent with [19] this explains that trainees join a training program with different intensions. Individuals with refusal goal orientation join a training program as they seek time out of work pressure or change or with a belief that training neither offers growth nor it improves/hinders one's performance. And high non-learning outcomes explain the beneficial effect of such goal orientation in training contexts. Refusal goal orientation may provide a new dimension to academic researchers and HRD practitioners to evaluate the effectiveness of training program in a better manner i-e it opens the door to evaluate the effectiveness of training programs in terms of non-learning outcomes.

Learning goal orientation has significant positive relation with training motivation and it reaps significant learning outcomes. These results are consistent with [33] and [34]. Performance goal orientation has a negative and significant relationship with training motivation. These results are consistent with [32]. Farr [32] suggested that performance goal orientations might be negatively related to training motivation if individuals infer that be- 
ing sent to training reflects management's negative evaluation of their performance. However performance goal orientation reaps significant learning outcomes. This may be due to the fact that trainees perceive that if they do not acquire the desired SKAs in a given training they may be negatively evaluated by their organization. So besides low motivation towards a training program they are able to focus on the learning content of a training program.

\subsection{Contributions to New Knowledge of HRM}

This study strives to open a discussion on third dimension of goal orientation that has a strong relationship with training motivation and training outcomes. Furthermore it is an initial effort to disclose the existence of nonlearning outcomes of a training program. These non-learning outcomes offer different implications for the design of effective training programs.

\subsection{Limitations of the Research}

The biggest limitation of this study is the extensive nature of the study that may have breached the exhaustive analysis of individual variables. Initially we felt that we have to make a choice between breadth and depth of the study, we focused more on breadth issues.

Furthermore sample size is insufficient to validate the ontology of two new concepts i-e refusal goal orientation and non-learning outcomes.

\subsection{Future Research}

This study introduces two new concepts to academic literature i-e Refusal goal orientation and non-learning outcomes of a training program. Existence of refusal goal orientation is studied from the perspective of one's perception i-e perception about growth opportunities and perception about the effectiveness of performance evaluation system. Other internal factors like personality traits and external factors like organizational culture, type of organization etc. should be studied to better understand the construct of refusal goal orientation. Longitudinal investigations should be made to understand whether refusal goal orientation is a static construct or change over time. Future studies should focus on identifying the relationship of non-learning outcomes of training program with employee commitment and organizational performance. It seems highly desirable to study refusal goal orientation in different organizational activities other than training. Cross cultural studies on refusal goal orientation may provide interesting insights to this concept. Besides all an explicit study on refusal goal orientation is needed.

Though the study is extensive yet limited numbers of antecedent variables were introduced at different levels of the proposed framework. It seems appropriate that the three levels of the framework should be studied independently while introducing extensive antecedent variables at each level to fulfill the "exhaustiveness" requirements. To start with, it would be appropriate to introduce job stress as another antecedent variable in the determination of goal orientation.

\subsection{Conclusions}

Goal orientation has three dimensions that include performance, learning and refusal. Perception about environmental factors like the effectiveness of performance evaluation system and growth opportunities are two antecedent factors that explain the three dimensions of goal orientation.

Unlike other personality traits, goal orientation is not a strong dispositional factor and is being affected significantly by contingencies. Performance goal orientation has a negative relationship with training motivation as individuals perceive that being sent to a training program is a sign of negative evaluation of one's performance. Learning goal orientation has a positive relationship with training motivation as individuals perceive training as a great opportunity for learning new things. Refusal goal orientation has positive relationship with training motivation because individuals perceive training as an opportunity to have time out of work and routine. Furthermore training program is seen as an opportunity to meet new people and visit new places.

Training motivation has a positive relationship with learning and non-learning outcomes of a training program. Learning goal orientation reaps significant learning and non-learning benefits. Performance goal orientation has significant learning outcomes while refusal goal orientation has significant non-learning outcomes. 
This study suggests that the evaluation of training programs should not be restricted to the SKAs and we must look into the other invisible effects of training programs on employees. It seems important to understand the effect of training programs on trainees, especially in the organizational context.

The findings of this study offer useful insights for academicians and practitioners. For academic researchers, identification of refusal goal orientation is an opportunity to explore the goal orientation construct in a more comprehensive way. So far research conducted on the construct offers classification of existing dimensions [10] [13] [58]. This study offers goal orientation as a state variable and studies it from the context of perception about organizational system. To fully understand the dynamics of it, it seems important to study it with other organizational variables like structure and culture. It may be interesting to study it with other individual variables like personality and self efficacy. Effect of demographical variables on refusal goal orientation may give better insight of the construct. Effect of refusal goal orientation on other individual level outcomes like OCB and deviant behavior is another avenue for research. Similarly non-learning outcomes of training program offer that researchers must understand that effectiveness studies in training require going beyond the evaluation of training on SKAs and must incorporate studies that tend to gauge effectiveness holistically. For researcher, experimental designs would be appropriate to study the learning and non-learning effects of a training program. Finally, it is important to explore that whether these non-learning outcomes are beneficial for organizations, especially taking into consideration the high cost of training.

This study proposes that practitioners must understand the relationship among goal orientation, training motivation and outcomes. The conventional need-analysis, at individual level, largely focuses on the identification of SKA deficiencies and thus helps mainly in selection of candidates for a given training. The findings of the study suggest that if evaluation of goal orientation and training motivation is augmented with the need analysis, it may be helpful to decision makers to identify an appropriate selection of candidate, training design, implementation and evaluation of training. So far it seems that refusal goal orientation has weak relationship with learning outcomes. To enhance learning for such candidates OD interventions may be identified based on the goal orientation information. For trainers, in the endeavor of a training design, goal orientation information may be helpful in identifying group profiles and making necessary augmentations in the training program.

\section{References}

[1] Elangovan, A.R. and Karakowsky, L. (1999) The Effects of Trainee and Environmental Factors on Transfer of Training: A Framework for Research. Leadership and Organizational Development Journal, 20, 268-275. http://dx.doi.org/10.1108/01437739910287180

[2] Blanchard, N.P. and Thacker, W.J. (2004) Effective Training: Systems, Strategies, and Practices. 2nd Edition, Pearson Education, India.

[3] Kitching, J. and Blackburn, R. (1999) Management Training and Networking in Small and Medium-Sized Enterprises in Three European Regions: Implications for Business Support, Environment and Planning. Government and Policy, 17, 621-635. http://dx.doi.org/10.1068/c170621

[4] Campanelli, P., Channell, J., McCauley L., Renouf, A. and Thomas, R. (1994) Training: An Explanation of the Word and Concept with an Analysis of the Implications for Survey Design. Employment Department, Research Series, 30.

[5] Colquitt, J.A., LePine, J.A. and Noe, R.A. (2000) Toward an Integrative Theory of Training Motivation: A MetaAnalytic Path Analysis of 20 Years of Research. Journal of Applied Psychology, 85, 679-707. http://dx.doi.org/10.1037/0021-9010.85.5.678

[6] Elliot, A.J. and McGregor, H.A. (2001) A $2 \times 2$ Achievement Goal Framework. Journal of Personality and Social Psychology, 80, 501-518. http://dx.doi.org/10.1037/0022-3514.80.3.501

[7] Towler, A.J. and Dipboye, R.L. (2001) Effects of Trainer Expressiveness, Organization, and Trainee Goal Orientation on Training Outcomes. Journal of Applied Psychology, 86, 664-673. http://dx.doi.org/10.1037/0021-9010.86.4.664

[8] Brown, K.G. (2001) Using Computers to Deliver Training: Which Employees Learn and Why? Personnel Psychology, 54, 271-296. http://dx.doi.org/10.1111/j.1744-6570.2001.tb00093.x

[9] Chiaburu, D.S. and Tekleab, A.G. (2005) Individual and Contextual Influences on Multiple Dimensions of Training Effectiveness. Journal of European Industrial Training, 29, 604-626. http://dx.doi.org/10.1108/03090590510627085

[10] Dweck, C.S. (1989) Motivation. In: Lesgold, A. and Glaser, R., Eds., Foundations for a Psychology of Education, Hillsdale, Erlbaum, 87-136.

[11] Dweck, C.S. and Leggett, E.L. (1988) A Social-Cognitive Approach to Motivation and Personality. Psychological Review, 95, 256-272. http://dx.doi.org/10.1037/0033-295X.95.2.256 
[12] Elliot, A.J. (1999) Approach and Avoidance Motivation and Achievement Goals. Educational Psychologist, 34, 169188. http://dx.doi.org/10.1207/s15326985ep3403_3

[13] Elliot, A.J. and McGregor, H.A. (1999) Test Anxiety and the Hierarchical Model of Approach and Avoidance Achievement Motivation. Journal of Personality and Social Psychology, 76, 628-644. http://dx.doi.org/10.1037/0022-3514.76.4.628

[14] Vande Walle, D. and Cummings, L.L. (1997) A Test of the Influence of Goal Orientation on the Feedback-Seeking Process. Journal of Applied Psychology, 82, 390-400. http://dx.doi.org/10.1037/0021-9010.82.3.390

[15] Vande Walle, D., Cron, W.L. and Slocum, J.W.J. (2001) The Role of Goal Orientation Following Performance Feedback. Journal of Applied Psychology, 86, 629-640. http://dx.doi.org/10.1037/0021-9010.86.4.629

[16] Ford, J.K., Smith, E.M., Weissbein, D.A., Gully, S.M. and Salas, E. (1998) Relationships of Goal Orientation, Metacognitive Activity and Practice Strategies with Learning Outcomes and Transfer. Journal of Applied Psychology, 83, 218-232. http://dx.doi.org/10.1037/0021-9010.83.2.218

[17] Dweck, C.S. (1986) Motivational Processes Affect Learning. American Psychologist, 41, 1040-1048. http://dx.doi.org/10.1037/0003-066X.41.10.1040

[18] Payne, C.S., Youngcourt, S.S. and Beaubien, J.M. (2007) A Meta-Analytic Examination of the Goal Orientation Nomological Net. Journal of Applied Psychology, 92, 128-150. http://dx.doi.org/10.1037/0021-9010.92.1.128

[19] Howard, J.K., Noe, A.R. and Wang, C. (2006) Motivation to Learn and Course Outcomes: The Impact of Delivery Mode, Learning Goal Orientation, and Perceived Barriers and Enablers. Personnel Psychology, 59, 665-702. http://dx.doi.org/10.1111/j.1744-6570.2006.00050.x

[20] Blau, P. (1964) Exchange and Power in Social Life. Wiley, New York.

[21] Wayne, S.J., Shore, L.M. and Liden, R.C. (1997) Perceived Organizational Support and Leader-Member Exchange: A Social Exchange Perspective. Academy of Management Journal, 40, 82-111. http://dx.doi.org/10.2307/257021

[22] Gouldner, A.W. (1960) The Norm of Reciprocity: A Preliminary Statement. American Sociological Review, 25, 161178. http://dx.doi.org/10.2307/2092623

[23] Potosky, D. and Ramakrishna, V. (2002) The Moderating Role of Updating Climate Perceptions in the Relationship between Goal Orientation, Self-Efficacy and Job Performance. Human Performance, 15, 275-297. http://dx.doi.org/10.1207/S15327043HUP1503_03

[24] Lim, D.H. and Johnson, S.D. (2002) Trainee Perceptions of Factors That Influence Learning Transfer. International Journal of Training and Development, 6, 36-48. http://dx.doi.org/10.1111/1468-2419.00148

[25] Colquitt, J.S. and Simmering, M.J. (1998) Conscientiousness, Goal Orientation, and Motivation to Learn during the Learning Process: A Longitudinal Field Study. Journal of Applied Psychology, 83, 654-664. http://dx.doi.org/10.1037/0021-9010.83.4.654

[26] Rouiller, J.Z. and Goldstein, I.L. (1993) The Relationship between Organizational Transfer Climate and Positive Transfer of Training. Human Resource Development Quarterly, 4, 377-390. http://dx.doi.org/10.1002/hrdq.3920040408

[27] Rasool, A.H., Bashir, A.F. and Azam, I.R. (2010) Pre-Training Motivation and the Effectiveness of Transformational Leadership Training: An Experiment. Academy of Strategic Management Journal, 9, 123-131.

[28] Mathieu, J.E. and Martineau, J.W. (1997) Individual and Situational Influences in Training Motivation. In: Ford, J.K., Kozlowski, S.W.J., Kraiger, K., Salas, E. and Teachout, M.S., Eds., Improving Training Effectiveness in Work Organizations, LEA, Mahwah, 193-222.

[29] Ree, M.J. and Earles, J.A. (1991) Predicting Training Success: Not Much More than g. Personnel Psychology, 44, 321-332. http://dx.doi.org/10.1111/j.1744-6570.1991.tb00961.x

[30] Mathieu, J.E., Martineau, J.W. and Tannenbaum, S.I. (1993) Individual and Situational Influences on the Development of Self-Efficacy: Implications for Training Effectiveness. Personnel Psychology, 46, 125-146. http://dx.doi.org/10.1111/j.1744-6570.1993.tb00870.x

[31] Brett, J.F. and Vande Walle, D. (1999) Goal Orientation and Specific Goal Content as Predictors of Performance Outcomes in a Training Program. Journal of Applied Psychology, 84, 863-872. http://dx.doi.org/10.1037/0021-9010.84.6.863

[32] Farr, J.L., Hofmann, D.A. and Ringenbach, K.L. (1993) Goal Orientation and Action Control Theory: Implications for Industrial and Organizational Psychology. In: Cooper, C.I. and Robertson, I.T., Eds., International Review of Industrial and Organizational Psychology, Wiley, Chichester, 193-232.

[33] Fisher, S.L. and Ford, J.K. (1998) Differential Effects of Learner Effort and Goal Orientation on Two Learning Outcomes. Personnel Psychology, 51, 397-420. http://dx.doi.org/10.1111/j.1744-6570.1998.tb00731.x

[34] Vande Walle, D., Cron, W.L. and Slocum, J.W.J. (2001) The Role of Goal Orientation Following Performance Feed- 
back. Journal of Applied Psychology, 86, 629-640. http://dx.doi.org/10.1037/0021-9010.86.4.629

[35] Matteson, T.M. and Ivancevich, M.J. (1987) Controlling Work Stress: Effective Human Resource and Management Strategies. Jossey Bass Business and Management Series, New York.

[36] Klein, H.J., Noe, R.A. and Wang, C. (2006) Motivation to Learn and Course Outcomes: The Impact of Delivery Mode, Learning Goal Orientation and Perceived Barriers and Enablers. Personnel Psychology, 59, 665-702. http://dx.doi.org/10.1111/j.1744-6570.2006.00050.x

[37] Cohen, D.J. (1990) What Motivates Trainees? Training \& Development Journal, 36, 91-93.

[38] Noe, R.A. and Schmitt, N. (1986) The Influence of Trainee Attitudes on Training Effectiveness: Test of a Model. Personnel Psychology, 39, 497-523. http://dx.doi.org/10.1111/j.1744-6570.1986.tb00950.x

[39] Tracey, J.B., Timothy, R. and Mathieu, J.E. (2001) The Influence of Individual Characteristics and the Work Environment on Varying Levels of Training Outcomes. Human Resource Development, 12, 5-23. http://dx.doi.org/10.1002/1532-1096(200101/02)12:1<5::AID-HRDQ2>3.0.CO;2-J

[40] Maurer, T.J. and Tarulli, B.A. (1994) Investigation of Perceived Environment, Perceived Outcome, and Person Variables in Relationship to Voluntary Development Activity by Employees. Journal of Applied Psychology, 79, 3-14. http://dx.doi.org/10.1037/0021-9010.79.1.3

[41] Noe, R.A. and Wilk, S.L. (1993) Investigation of the Factors That Influence Employee's Participation in Development Activities. Journal of Applied Psychology, 78, 291-302. http://dx.doi.org/10.1037/0021-9010.78.2.291

[42] Ryman, D.H. and Biersner, R.J. (1975) Attitudes Predictive of Driving Success. Personnel Psychology, 28, $181-188$. http://dx.doi.org/10.1111/j.1744-6570.1975.tb01379.x

[43] Cheng, E.W.L. and Ho, D.C.K. (2001) A Review of Transfer of Training Studies in the Past Decade. Personnel Review, 30, 102-117. http://dx.doi.org/10.1108/00483480110380163

[44] Axtell, C.M. and Maitlis, S. (1997) Predicting Immediate and Longer-Term Transfer of Training. Personnel Review, 26, 201-212. http://dx.doi.org/10.1108/00483489710161413

[45] Tannenbaum, S.I. and Yukl, G. (1992) Training and Development in Work Organizations. Annual Review of Psychology, 43, 399-441. http://dx.doi.org/10.1146/annurev.ps.43.020192.002151

[46] Noe, R.A. (1986) Trainees' Attributes and Attitudes: Neglected Influences on Training Effectiveness. Academy of Management Review, 11, 736-749.

[47] Kitching, J. and Blackburn, R. (1999) Management Training and Networking in Small and Medium-Sized Enterprises in Three European Regions: Implications for Business Support, Environment and Planning. Government and Policy, 17, 621-635. http://dx.doi.org/10.1068/c170621

[48] Campanelli, P., Channell, J., McCauley, L., Renouf, A. and Thomas, R. (1994) Training: An Explanation of the Word and Concept with an Analysis of the Implications for Survey Design. Employment Department, Research Series, London.

[49] Lingg, M.A. (1996) Training for Job-Skill Confidence. Journal of Career Development, 22, 261-271. http://dx.doi.org/10.1177/089484539602200404

[50] Weaver, M. (1996) Empowering Employees through Basic Skill Training. Quality Resources Inc., New York.

[51] Wilson, F. (1994) Introducing New Computer-Based Systems at Zenbank. Technology, Work and Employment, 9, 115125. http://dx.doi.org/10.1111/j.1468-005X.1994.tb00055.x

[52] Austrin, T. (1991) Flexibility, Surveillance and Hype in New Zealand Retailing. Work, Employment and Society, 5, 201-220. http://dx.doi.org/10.1177/0950017091005002004

[53] Baldwin, T.T., Magjuka, R.J. and Loher, B.T. (1991) The Perils of Participation: Effects of Choice of Training on Trainee Motivation and Learning. Personnel Psychology, 44, 51-65. http://dx.doi.org/10.1111/j.1744-6570.1991.tb00690.x

[54] Martocchio, J.J. and Webster, J. (1992) Effects of Feedback and Cognitive Playfulness on Performance in Microcomputer Software Training. Personnel Psychology, 45, 553-577. http://dx.doi.org/10.1111/j.1744-6570.1992.tb00860.x

[55] Quinones, M.A. (1995) Pre-training context effects: Training assignment as feedback. Journal of Applied Psychology, 80: 226-238. http://dx.doi.org/10.1037/0021-9010.80.2.226

[56] Tannenbaum, S.I., Mathieu, J.E., Salas, E. and Cannon-Bowers, J.A. (1991) Meeting Trainees’ Expectations: The Influence of Training Fulfillment on the Development of Commitment, Self-Efficacy, and Motivation. Journal of Applied Psychology, 76, 759-769. http://dx.doi.org/10.1037/0021-9010.76.6.759

[57] Preacher, K.J. and Hayes, A.F. (2004) SPSS and SAS Procedures for Estimating Indirect Effects in Simple Mediation Models. Behavior Research Methods, Instruments and Computers, 36, 717-731.

http://dx.doi.org/10.3758/BF03206553 
[58] Button, S.B., Mathieu, J.E. and Zajac, D.M. (1996) Goal Orientation in Organizational Research: A Conceptual and Empirical Foundation. Organizational Behavior and Human Decision Processes, 67, 26-48.

http://dx.doi.org/10.1006/obhd.1996.0063

[59] Williams, J.R. and Levy, P.E. (1992) The Effects of Perceived System Knowledge on the Agreement between Self Rating and Supervisor Rating. Personal Psychology, 45, 835-847. http://dx.doi.org/10.1111/j.1744-6570.1992.tb00970.x 


\section{Appendix: Questionnaire Items}

Note: Responses range from 1 (strongly disagree) to 7 (strongly agree).

\section{Goal Orientation}

Performance Goal Orientation (PGO)

1) I prefer to do things that I can do well rather than things that I do poorly.

2) I.am happiest at work when I perform tasks on which I know that I won't make any errors.

3) The things I enjoy the most are the things I do the best.

4) The opinions others have about how well I can do certain things are important to me.

5) I feel smart when I can do something without making any mistakes.

6) I like to be fairly confident that I can successfully perform a task before I attempt it.

7) I like to work on tasks that I have done well on in the past.

8) I feel smart when I can do something better than most people.

Learning Goal Orientation (LGO)

1) The opportunity to do challenging work is important to me.

2) When I fail to complete a difficult task, I plan to try harder the next time I work on it.

3) I prefer to work on tasks that force me to learn new things.

4) The opportunity to learn new things is important to me.

5) I do my best when I am working on a fairly difficult task.

6) I try hard to improve my past performance.

7) The opportunity to extend the range of my abilities is important to me.

8) When I have difficulty solving a problem, I enjoy trying different approaches to see which one will work. Refusal Goal Orientation (RGO)

1) I would be happy to have some free time during job for non-job activities.

2) I make other people realize that I am performing better than others.

3) I believe that challenging work does not offer any opportunity for development.

4) The way people evaluate my performance is not important to me.

5) I would be happy if I am allowed to leave work for few days without any penalty.

6) I believe that performing worse does not offer any threat to me.

7) I continue doing my job without considering how people perceive it.

8) I feel that learning new things will help perform my job in a better manner.

9) I am excited to meet new people.

10) I like to travel and visit new places.

11) I involve myself in assignments that develop my work abilities.

12) I look for activities that may give me escape from routine work.

13) I take on new assignments that may be irrelevant to my work requirements.

\section{Training Motivation (TM)}

1) I consider training program as a superior activity.

2) I am always willing to attend a training program.

3) I am disappointed if I loose an opportunity to attend a training program.

4) I prefer trainings programs over office work.

5) Being nominated for a training program is always good news for me.

6) I am excited when I plan for attending a training program.

\section{Training Program Outcomes}

Learning Outcomes

1) Training program was helpful in learning new skills.

2) Training program increased my knowledge that would be helpful in performing my job.

3) Training program has increased my work abilities.

4) Training program was helpful in developing managerial competencies.

5) I have learned many job related things from this training program.

Non-Learning Outcomes 
1) I feel fresh to take on job challenges after the training program.

2) Training program has increased my motivation towards work.

3) Training program provided time out of work that would be helpful in reducing job stress.

4) I am thankful to my company for providing training opportunity.

5) Training programs like this one would increase my respect towards my organization.

6) Training would be helpful for my colleagues to develop a positive attitude towards work.

7) Training program has boosted my confidence.

8) I would feel more comfortable with my organization after the training program.

9) Training program was a waste of time for me.

\section{Perception about performance evaluation system}

1) Performance evaluation system is able to identify performers and non-performers.

2) Based on performance evaluation, employees are either penalized or rewarded.

3) In my organization, performance evaluation system poses challenge for employees to perform better.

\section{Perception about growth opportunities}

1) There are various opportunities for development in the environment. .

2) If I would be able to secure new skills I would be able to excel in my career.

3) More learned employees are always preferred over less learned employees.

4) Employees should focus on learning new skills. 